\title{
Evaluation of the Histomorphological and Toxicological Changes in Rodents after treatment with Hydroethanolic Extract of the Secamone Afzelii Aerial Parts
}

\author{
G. O. Mbaka ${ }^{1}$ T. E. Akala² \\ ${ }^{1}$ Department of Anatomy, Lagos State University College of Medicine, \\ Ikeja, Lagos, Nigeria \\ 2 Department of Anatomy, Faculty of Basic Medical Sciences, Olabisi \\ Onabanjo University, Ikenne, Nigeria
}

\begin{abstract}
Address for correspondence G. O. Mbaka, PhD, Department of Anatomy, Lagos State University College of Medicine, Ikeja, Lagos, Nigeria (e-mail: mbaaka2gm@gmail.com; mbaakagm@gmail.com).
\end{abstract}

J Morphol Sci 2018;35:233-241.

\begin{abstract}
Objective To evaluate the histomorphological and toxicological changes in rodents after treatment with hydroethanolic extract of the Secamone afzelii aerial parts.

Materials and Methods An acute toxicity study on Swiss albino mice of both sexes was performed. Administration of a single dose of $2,000 \mathrm{mg} / \mathrm{kg}^{-1}$ of body weight (bwt) of $S$. afzelii extract by gavages to 5 mice showed no mortality; hence, a $1 / 10^{\text {th }}$ dose was used as the highest therapeutic dose. The intra-peritoneal administration produced dose-dependent mortality, with median lethal dose $\left(L_{50}\right)$ being $\sim 281.8 \mathrm{mg} / \mathrm{kg}^{-1}$. In a subacute toxicity study, Wistar rats received daily administration of the extract in the dose range of 50 to $200 \mathrm{mg} / \mathrm{kg}$ bwt for 35 days. Its effects on histological, biochemical and hematological parameters were evaluated.

Results There was an initial body weight decrease in all the treated animals in the first 7 days. Thereafter, increase in body weight was observed. The treated animals also exhibited organ weight increase when compared with the control. Statistically significant increase $(p<0.05)$ in aspartate aminotransferase (AST) occurred in the extract treated animals, whereas alanine aminotransferase (ALT) showed a statistically insignificant $(p \geq 0.05)$ increase when compared with the control. Total plasma protein (TPP) and albumin (ALB) also exhibited insignificant $(p \geq 0.05)$ increases, while total bilirubin (T. BIL) decreased compared with the control. Insignificant $(p \geq 0.05)$ changes also occurred in the plasma creatinine and urea levels in the extract treated animals when compared with the control group. The liver tissue histology showed no

Keywords

- secamone afzelii

- tissue histology

- acute and subacute toxicities hepatocellular damage. However, inflammatory changes occurred in the testicular tissue, in which a quantitative decrease in spermatogenic cells was observed due to extensive cellular necrosis, leaving only the basement layer of the seminiferous tubules. Conclusion S. afzelii exhibited a high safety margin, an indication that it is safe for consumption. However, after chronic administration, it caused undesirable effect in the testes that could compromise its fertility function.
\end{abstract}

received

September 19, 2018

accepted

September 17, 2018
DOI https://doi.org/

10.1055/s-0038-1675793. ISSN 2177-0298.
Copyright $(2018$ by Thieme Revinter

Publicações Ltda, Rio de Janeiro, Brazil
License terms

(c) $(1) \$$ 


\section{Introduction}

The use of plants or compounds derived from plants as therapeutic agents against various human and animal diseases is an age-long practice. Phytomedicine is renowned as the most common form of alternative medicine and is used by $\sim 80 \%$ of the world population mainly among the Asians and Africans, with growing awareness among the Europeans, Americans and other developed countries where modern medicine is predominantly used. ${ }^{1,2}$ The popularity of phytomedicine has continued to increase in spite of the giant stride and wide application of modern medicine. Its rising popularity is accounted for mainly due to the advantage of being an efficacious and cheap source of medical care. The high reliance in herbal medicine may be due to misconception that herbal products are devoid of adverse and toxic effects associated with conventional and allopathic medicines.

Toxicity can be considered as the degree to which a chemical compound could harm humans, animals or plants. A toxic agent usually has a target organ; therefore, its toxicity profile can be measured by its effects on that organ. ${ }^{3}$ More often, besides the primary target organ, the liver could also be affected because of its role in synthesis. A central concept to toxicity is that its effect is dose-dependent. ${ }^{3}$ What this means is that, if consumed above the appropriate dose, medication, whether herbal or allopathic, will create toxic effect to the body system.

It is instructive to note that herbs used in the treatment of different ailments usually contain a wide range of chemical compounds, which apart from being of beneficial effect to the body may also contain ingredients that have adverse effects to its component parts. ${ }^{4}$ Incidences of adverse effects and sometimes life-threatening conditions emanating from these herbal medicines have been reported. ${ }^{5-8}$ A major factor to adverse health conditions caused by herbal medication is lack of standardization, resulting in indiscriminate use without appropriate dose. It is unfortunate that most of the cases of affected individuals are undocumented because the people predominantly affected are rural dwellers with high reliance on herbal medicine. The absence of reliable statistics of the affected cases has undermined the alarming nature of its negative impact, particularly to this vulnerable group. Although it is difficult to quantify the morbidity and mortality levels of the affected cases, their incidence calls for global attention to toxicity profiling of medicinal plants, even though they have been used for ages, to enable the documentation of their safety/risk potentials.

Secamone afzelii is an herbal therapy that has wide application. It belongs to the Asclepiadaceae family and is widespread in West and Central Africa. ${ }^{9}$ It is mainly found in secondary forest and savanna thickets, being more common in abandoned fields and field boundaries growing in a wide range of climatic conditions, particularly in the sun or in the light shade. ${ }^{9}$ Its medicinal value includes the use in the treatment of gonorrhea, cough and catarrh and as galactogogue. ${ }^{10}$ Its leafy twig infusion is taken to treat sexually transmitted diseases, diabetes and schistosomiasis. ${ }^{11}$ Its use in the treatment of benign prostatic hyperplasia (BPH) has also been reported. ${ }^{12}$ The phytochemical study of $S$. afzelii revealed a high concentration of flavonoids, saponins, reducing sugars, coumarins and the triterpenoid friedelin. ${ }^{13}$ Because of the wide application of $S$. afzelii by the traditional healers, it was found necessary to evaluate its toxicity profile.

\section{Materials and Methods}

\section{Plant Materials}

The aerial part of S. afzelii was collected from Ikenne-Remo, Ogun State, Nigeria. The plant sample was authenticated in the Forestry Research Institute of Nigeria (FRIN), Ibadan, where the voucher specimen was deposited in the herbarium (FHI/108940).

\section{Preparation of Hydroethanol Extract of Sacamone Afzelii}

The aerial part of the plant was dried in the sun within the temperature range of 30 to $42^{\circ} \mathrm{C}$ for 5 days before being subjected to size reduction with an electric grinder until it turned into a coarse powder. The coarse powder of the plant, weighing $780 \mathrm{~g}$, was extracted with $90 \%$ aqueous ethanol in 3 cycles using a Soxhlet extractor. The crude extract was filtered with Whatman filter paper No. 4 (GE Healthcare UK ltd Buckghamshire HP7 9NA, UK) and the filtrate was concentrated in vacuo at $30^{\circ} \mathrm{C}$ to obtain $68 \mathrm{~g}$ of residue weight $(8.7 \% \mathrm{w} / \mathrm{w})$. The residue was stored in an air tight bottle kept in a refrigerator at $4^{\circ} \mathrm{C}$ until used.

\section{Animals}

Adult male Wister rats (200 $\pm 5 \mathrm{~g}$ ) obtained from the Animal House of the University of Ibadan, Oyo State, Nigeria, were kept under the standard environmental condition of 12/ 12 hour light/dark cycle. They were housed in polypropylene cages (five animals per cage) and were maintained on mouse chow (Livestock Feeds Nigeria Ltd.) and provided with water ad libitum. They were allowed to acclimatize to the laboratory conditions for 12 days before the experiment. The use and care of the animals, and the experimental protocol were in strict compliance with the Institute of Laboratory Animals Research (ILAR) guidelines on the use and care of animals, in experimental studies. $^{14}$

\section{Acute Toxicity Study}

Fifteen Swiss albino mice, fasted for 14 hours, were administered with $S$. afzelii extract dispersed in acacia solution (2\% $\mathrm{w} / \mathrm{v}$ ) intraperitoneally in graded doses of 125,250 and 500 $\mathrm{mg} / \mathrm{kg}^{-1}$, with 5 mice per group, until $100 \%$ mortality was recorded. The control group of 5 mice was given $0.3 \mathrm{ml} / \mathrm{kg}^{-1}$ (bwt) of acacia solution. The median lethal dose $\left(\mathrm{LD}_{50)}\right.$ was calculated using the method of Miller and Tanter. ${ }^{15}$ Another group of 5 mice, fasted for 14 hours, were administered a single dose of $2,000 \mathrm{mg} / \mathrm{kg}^{-1}$ (bwt) of $S$. afzelii extract by gavages and then observed for 7 days for mortality and physical/behavioral changes. The animals did not show any mortality at the dose administered; hence, the $1 / 10^{\text {th }}$ dose, which was $200 \mathrm{mg} / \mathrm{kg}^{-1}$ (bwt), was chosen as the highest dose, and graded dose decreases of 100 and $50 \mathrm{mg} / \mathrm{kg}^{-1}$ (bwt) were also used as therapeutic doses. ${ }^{15}$ 


\section{Subacute Toxicity Study}

A total of 20 male and female ten-week-old rats weighing 140 to $150 \mathrm{~g}$ were randomly allotted, 5 per group, to the control and the extract-treated groups. After fasting the animals overnight, the control group received a dose of $0.6 \mathrm{ml} \mathrm{mg} / \mathrm{kg}$ ${ }^{-1}$ of acacia $(2 \% \mathrm{w} / \mathrm{v})$ solution and the treated received 50,100 and $200 \mathrm{mg} / \mathrm{kg}^{-1}$ of the extract dispersed in acacia $(2 \% \mathrm{w} / \mathrm{v})$ solution. The doses were administered by gavages daily for a period of 35 days. ${ }^{16,17}$ The animals were observed closely for any behavioral changes, body weight changes and mortality and were later sacrificed for biochemical and hematological investigations and organs histological changes.

\section{Biochemical Parameters}

Following the sacrifice under mild diethyl ether, blood was collected via cardiac puncture in two tubes. The ethylenediaminetetraacetic acid (EDTA) tube was used to collect blood for the analysis of hematological parameters, while the second tube with heparin was used to separate plasma from blood for biochemical estimations. The collected blood was centrifuged within 20 minutes of collection at 4,000 rpm for 10 minutes to obtain the blood plasma, which was analyzed for total cholesterol, triglyceride and high-density lipoprotein cholesterol (HDL-cholesterol) levels by modified enzymatic procedures from Sigma Diagnostics by modified enzymatic method. ${ }^{18}$ The plasma was analyzed for alanine aminotransferase (ALT) activity, aspartate aminotransferase (AST) activity, and creatinine by standard enzymatic assay methods. ${ }^{19}$ The urea content was determined according to the Urease-Berthelot method. ${ }^{20}$ The protein content was determined using enzymatic spectroscopic methods. ${ }^{21}$ Total bilirubin was estimated using Jandrassik and Grof technique. ${ }^{22}$ Albumin was determined based on its reaction with bromocresol green (Binding method). ${ }^{23}$

\section{Hematological Parameters}

Hematocrit (HCT) was estimated using the method of Ekaidem et al. ${ }^{24}$ Hematocrit tubes were filled to mark with whole blood, and the bottom of the tubes sealed with plasticide and centrifuged for 4 to 5 minutes at $4,000 \mathrm{rpm}$ using an HCT centrifuge. The percentage cell volume was read by sliding the tube along a "critocap" chart until the meniscus of the plasma intersected the $100 \%$ line. Hemoglobin contents were determined using the Cyanmethemoglobin (Drabkin) method. ${ }^{24}$ Hematocrit was determined according to Ekaidem et $a{ }^{24}$ while white blood cells (WBCs) and its differentials (neutrophil, eosinophil, basophil, lymphocyte and monocyte) were determined as described by Dacie and Lewis. ${ }^{25}$ The blood samples were analyzed for red blood cells (RBCs) using the hemocytometic method. ${ }^{25}$

\section{Histology Slide Preparation}

The organs were fixed in $10 \%$ formal saline for 10 days. They were later removed from the preservative and dehydrated in increasing concentrations of alcohol; $70 \%, 80 \%, 90 \%$ and absolute alcohol (100\%). The organs were treated with acetone and then cleared in xylene for 30 minutes to enhance their tissue transparency, which was followed by impregnating and embedding them in paraffin wax. The embedded tissues were sectioned at $5 \mu \mathrm{m}$, mounted on slides and then rehydrated in descending grades of alcohol before staining with hematoxylin and eosin (H\&E) stains. ${ }^{15}$ The stained tissues were examined under a PoTop PD-PB sereies (OMETOP systems co., Itd 6FL, No. 176-1 Jhongshan 2nd Rd., Lujhou Dist., New Taipei City 247, Taiwan) light microscope (fitted with camera) at high power magnification (X100) for changes in organ architecture and photomicrographs taken.

\section{Statistical Analysis}

All values were expressed as mean \pm standard error of mean (SEM) and the statistical significance between treated and control groups was analyzed by means of the Student $t$-test, with $p<0.05$ and $p<0.01$ considered significant.

\section{Results}

\section{Acute Toxicity Study}

The acute toxicity study showed that the animals fed by gastric gavages tolerated up to $9 \mathrm{~g} / \mathrm{kg}^{-1}$ of the extract. The intraperitoneal (IP) administration produced dose dependent mortality with an $\mathrm{LD}_{50}$ of the extract at $281.8 \mathrm{mg} / \mathrm{kg}^{-1}$ (-Table1).

\section{Body and Organ Weights}

The effect of the extract on the organ weight of the control and treated animals is shown in $\mathbf{- T a b l e} \mathbf{2}$, and the percentage of increase in the body weight of the treated animals compared with the control is shown in - Fig. $\mathbf{1}$.

A decrease in body weight was observed in all the treated animals in the first 7 days of the treatment. However, from day 21 on, particularly in the low and medium dose treatments, the body weight of the animals showed progressive weight increase until the end of the experiment. Generally, there was insignificant $(p>0.01)$ increase in the organ weight of the treated animals compared with the control group.

\section{Tissue Histomorphology/Pathology}

Figs. 2-5 show the histological studies of the effects of S. afzelii extract on target organs. Tissue morphological alterations were examined in the treated groups compared with the control.

Table 1 Acute toxicity determination of the aerial part of Secamone afzelii (intraperitoneal route) at a dose range of 125 to $500 \mathrm{mg} / \mathrm{kg}^{-1}$

\begin{tabular}{|l|l|l|l|l|l|}
\hline Dose & Motility & \% Motility & Log Dose & Probit & Probit Approx. \\
\hline $125 \mathrm{mg} / \mathrm{kg}^{-1}$ & $1 / 5$ & 20 & 2.0969 & 4.1584 & 4.2 \\
\hline $250 \mathrm{mg} / \mathrm{kg}^{-1}$ & $2 / 5$ & 40 & 2.3979 & 4.7467 & 4.7 \\
\hline $500 \mathrm{mg} / \mathrm{kg}^{-1}$ & $4 / 5$ & 80 & 2.6989 & 45.8416 & 8.2 \\
\hline
\end{tabular}


Table 2 Data on the organ weight $\left(100 \mathrm{~g}^{-1}\right)$ in rats after sub-chronic treatment with S. Afzelii extract

\begin{tabular}{|l|l|l|l|l|l|}
\hline \multirow{2}{*}{ Treatment } & \multicolumn{4}{l|}{ Mean organ weight per $100 \mathrm{~g} \mathrm{body}^{-1}$} \\
\cline { 2 - 6 } & Heart & Lung & Liver & Kidney & Testes \\
\hline Control & $0.3 \pm 0.2$ & $1.9 \pm 0.5$ & $5.8 \pm 0.3$ & $1.0 \pm 0.3$ & $2.7 \pm 0.4$ \\
\hline $50 \mathrm{mg} / \mathrm{kg}^{-1}$ & $0.5 \pm 0.1$ & $2.1 \pm 0.2$ & $4.0 \pm 0.3$ & $1.5 \pm 0.0$ & $3.7 \pm 0.5$ \\
\hline $100 \mathrm{mg} / \mathrm{kg}^{-1}$ & $0.5 \pm 0.0$ & $2.1 \pm 0.2$ & $4.0 \pm 0.0$ & $1.5 \pm 0.2$ & $3.7 \pm 0.5$ \\
\hline $200 \mathrm{mg} / \mathrm{kg}^{-1}$ & $0.5 \pm 0.2$ & $2.2 \pm 0.1$ & $4.2 \pm 0.4$ & $1.6 \pm 0.3$ & $3.8 \pm 0.4$ \\
\hline
\end{tabular}

Mean \pm SEM, $(n=5){ }^{*} \mathrm{p}<0.05$ versus control group.

The hepatic tissue of the control ( - Fig 2A) showed normal architecture. It exhibited typical parenchymal appearance, though with indistinct hepatic lobules. The polygonal shaped hepatocytes were arranged as irregular cord-like structures interspaced by sinusoids, which showed normal convergence toward the central vein. In the animals treated with $200 \mathrm{mg} / \mathrm{kg}^{-1}$ (-Fig. 2B), the hepatic parenchyma exhibited no apparent inflammatory changes. The hepatic portal was remarkable with no sinusoidal congestion.

- Fig. 3A showed normal testis in which a cross section of seminiferous tubules indicated a tubular basement membrane supporting multilayered germinal epithelium. In the germinal epithelium were few unremarkable Sertoli cells that provided support to the spermatogenic cells. The organization of the spermatogenic cells arrangement are in strata with the most primitive (large spermatogonia), closest to the basement, while spermatids smaller in size showed projection toward the lumen with their tails forming a wavy appearance. In the animals that received $200 \mathrm{mg} / \mathrm{kg}^{-1}$ (-Fig. 3B), marked inflammatory changes occurred. There was severe tissue and cellular necrosis in the seminiferous tubules resulting in marked depletion in spermatogenic cells mass at the multilayered germinal epithelium. The cross section of the tubules showed residue of very scanty sperm cells with basement membrane largely exposed.

The renal tissue of the control group ( - Fig. 4A) showed the normal architecture of the renal cortical tissue, in which were renal corpuscles appeared as rounded structures surrounded by a narrow space, the Bowman's space. The cortical tubules seen in this section consisted mainly of proximal convoluted tubules with few of the distal convoluted tubules indicated. In the animals treated with $200 \mathrm{mg} / \mathrm{kg}^{-1}$ of the extract ( - Fig. 4B), no noticeable distortion was observed in the glomerular complex, convoluted tubules and in the cellular interstices, respectively.

The cardiac tissue of the control group ( - Fig. 5A) showed myocytes with deeply stained nuclei separated by unremarkable interstitium. In the treated animals (-Fig. 5B), the myocytes showed no variation compared with the control group.

\section{Chronic Toxicity Study}

The effects of the extract on the biochemical parameters were summarized in - Table 3. There was significant increase $(p<0.01)$ in aspartate aminotransferase (AST) at the doses administered, whereas alanine aminotransferase (ALT) showed insignificant $(p \geq 0.01$ ) increase in the treated animals when compared with the control group. Total plasma protein (TPP) exhibited insignificant $(p \geq 0.05)$ increase in all the doses administered. Albumin (ALB) equally showed insignificant increase in the two higher doses while significant $(p<0.05)$ increase was observed in the lowest extract dose. Total bilirubin (T. BIL) showed decrease compared with the control. There were insignificant $(p \geq 0.05)$ changes in the plasma creatinine and urea levels in the treated groups when compared with the control group. Alkaline phosphate (ALP) increased at low and medium extract dose treatments but exhibited decrease at the highest dose when compared with the control group. In the lipid profile study, there was insignificant $(p \geq 0.05)$ increase in total cholesterol (T. Chol.). Triglycerides (TG) exhibited marked

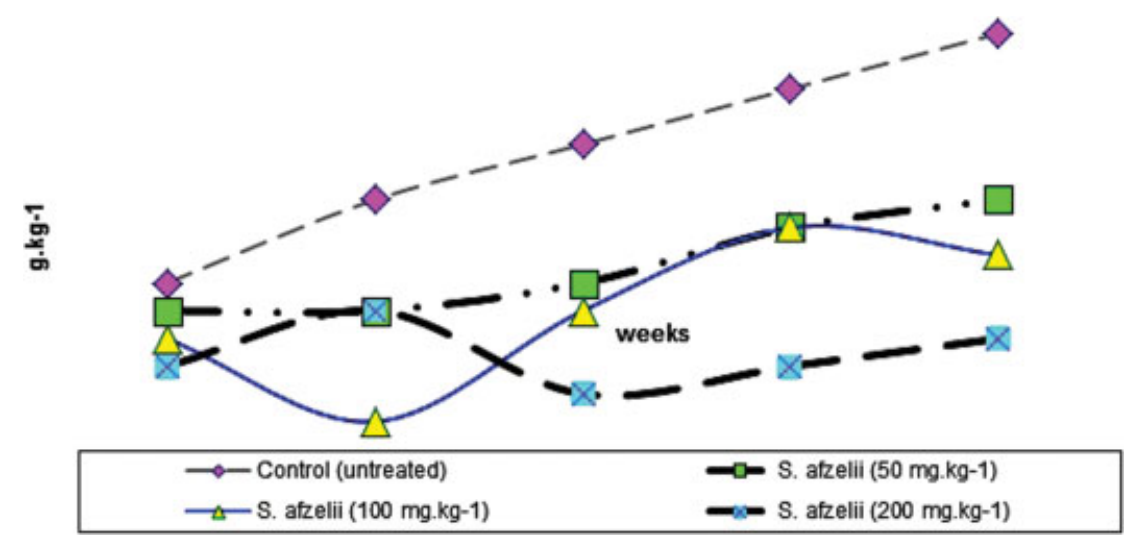

Fig. 1 Body weight differential in control and treated animals. 

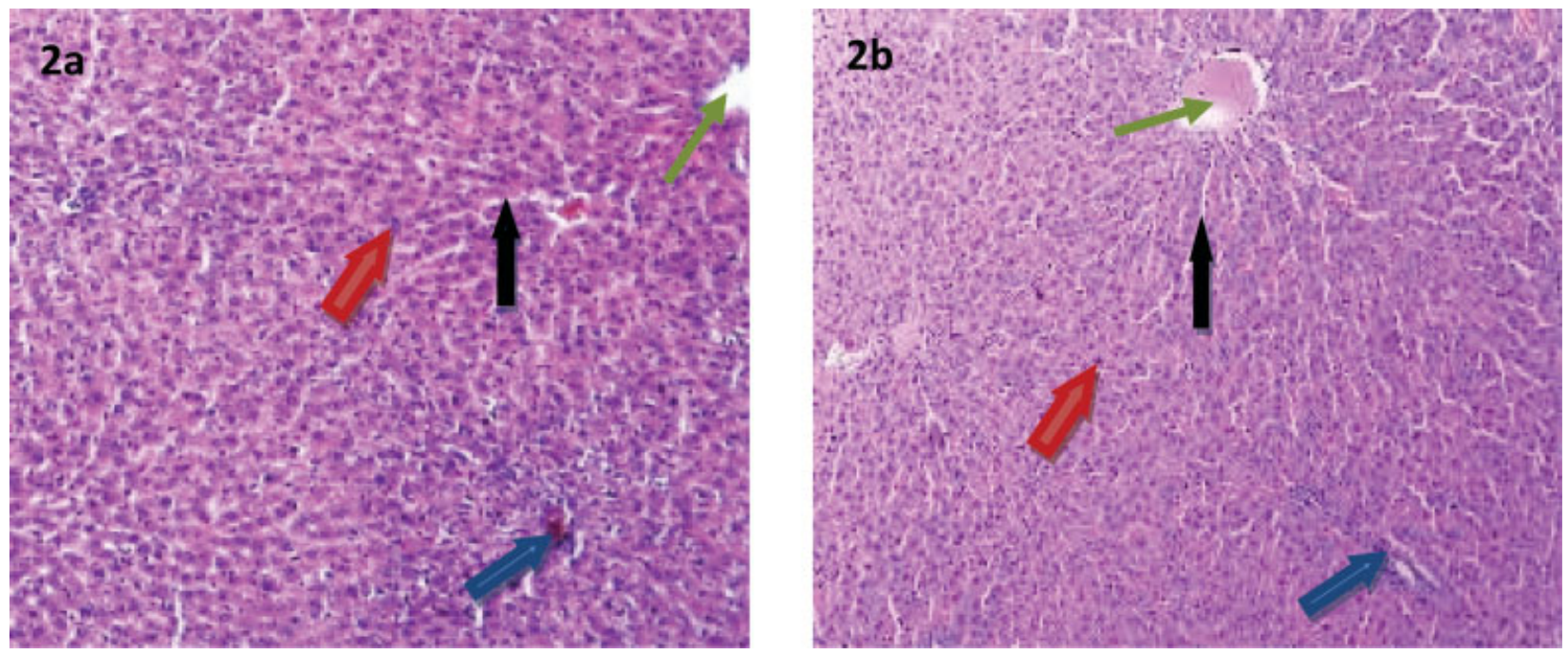

Fig. 2 (A) Photomicrograph of a cross section of normal hepatic tissue indicating portal tract (blue arrowed), hepatocytes (red arrowed), sinusoid (black arrowed) and central vein (green arrowed). Hematoxylin and eosin (H\&E) stained. Mag. X100. (B) Photomicrograph of a cross section of hepatic tissue treated with $200 \mathrm{mg} / \mathrm{kg}^{-1}$ of the extract showed no abnormality. Hematoxylin and eosin stained). Mag. X100.
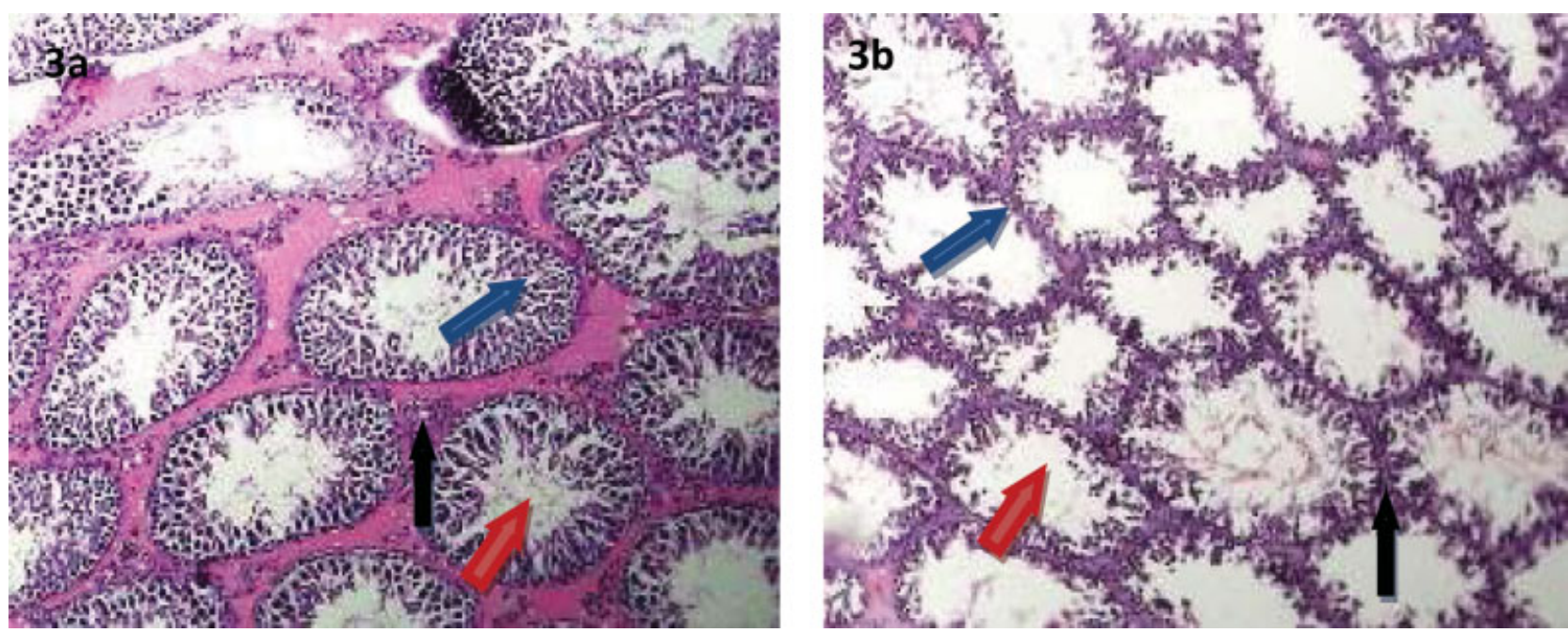

Fig. 3 (A) Photomicrograph of a cross section of normal testicular tissue indicating sperm cells (blue arrowed), interstitial cells of Leydig (black arrowed), and wavy tails of spermatozoa (red arrowed) (H\&E stained). Mag. X100. (B) Photomicrograph of a cross section of tissue treated with $200 \mathrm{mg} / \mathrm{kg}^{-1}$ of the extract indicating quantitative sperm cells decrease, exposed basement membrane (blue arrowed) with wide lumen (red arrowed). Hematoxylin and eosin stained. Mag. X100.

increase at low and highest dose of administration while high density lipoprotein (HDL) showed decrease when compared with the control group.

The effects of S. afzelii extract on the RBC components and differentials were summarized in -Table 4 . Insignificant decreases ( $p \geq 0.01)$ were observed in the RBCS and haemoglobin content in all the groups compared with the control. The packed cell volume (PCV) decreased at low and medium doses but increased at the highest dose treatment, while WBC count showed insignificant increase in all the doses compared with the control. The RBC indices, mean corpuscular volume (MCV), mean corpuscular hemoglobin $(\mathrm{MCH})$ and mean corpuscular hemoglobin concentration (MCHC) exhibited insignificant increases $(p \geq 0.01)$ when compared with the control group.

The effects of the extracts on WBC differentials are shown in -Table 5. Lymphocytes exhibited significant increase $(p<0.05)$. Neutrophil showed increase that was marked at the lowest dose. There were insignificant increases $(p \geq 0.01)$ in lymphocyte absolute (ABS) and in the mixed differential (MXD) when compared with the control group. Likewise, the platelets level increased markedly compared with the control.

\section{Discussion}

Plants used for medication are enriched with active principles. The type and the concentration of the active principle found in the diet and their metabolic clearance rate in the body are factors that may likely influence the toxicity of the plant. ${ }^{15}$ Therefore, the safety of plant medicine for human use can be determined by means of a toxicological evaluation, which is usually performed in various experimental 

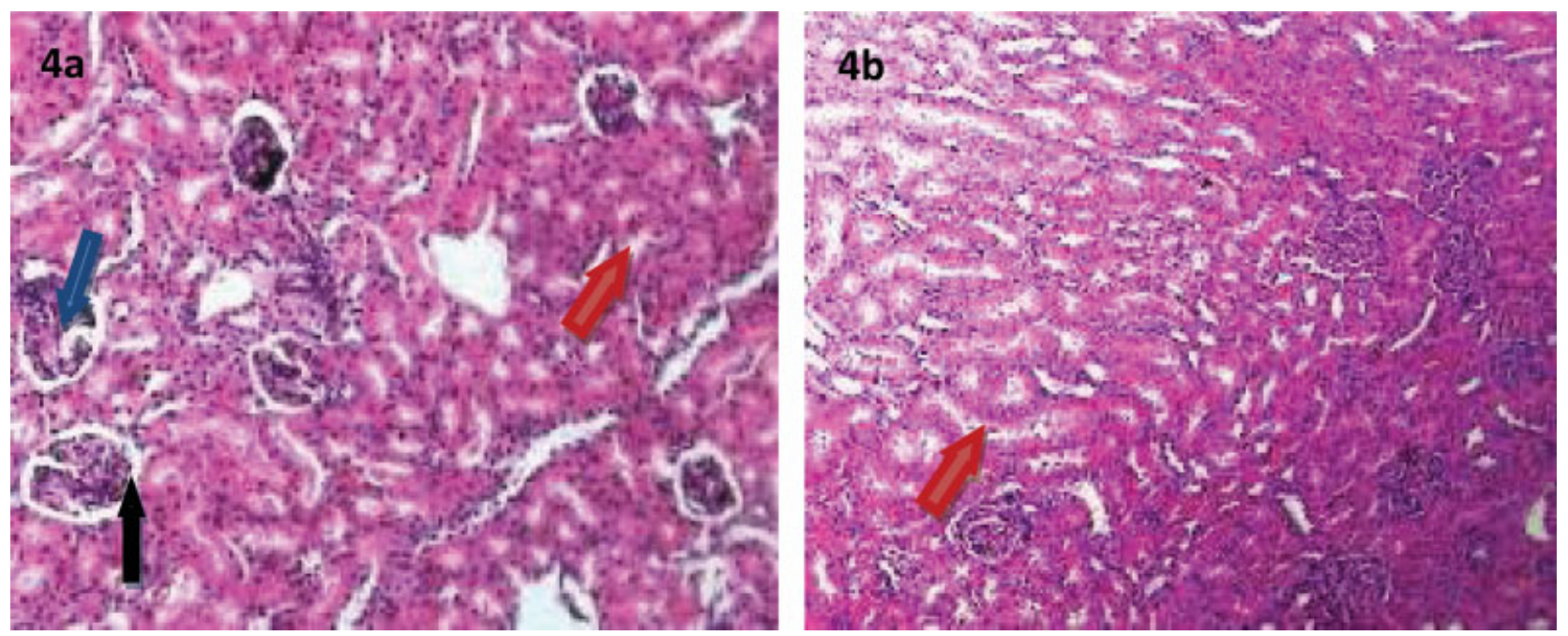

Fig. 4 (A) Photomicrograph of a cross section of normal renal tissue indicating glomerular complex (blue arrowed), Bowman capsule (black arrowed), and convoluted tubules (red arrowed). Hematoxylin and eosin stained. Mag. X100. (B) Photomicrograph of a cross section of renal tissue treated with $200 \mathrm{mg} / \mathrm{kg}^{-1}$ of the extract showed no abnormality. Hematoxylin and eosin stained. Mag. X100.
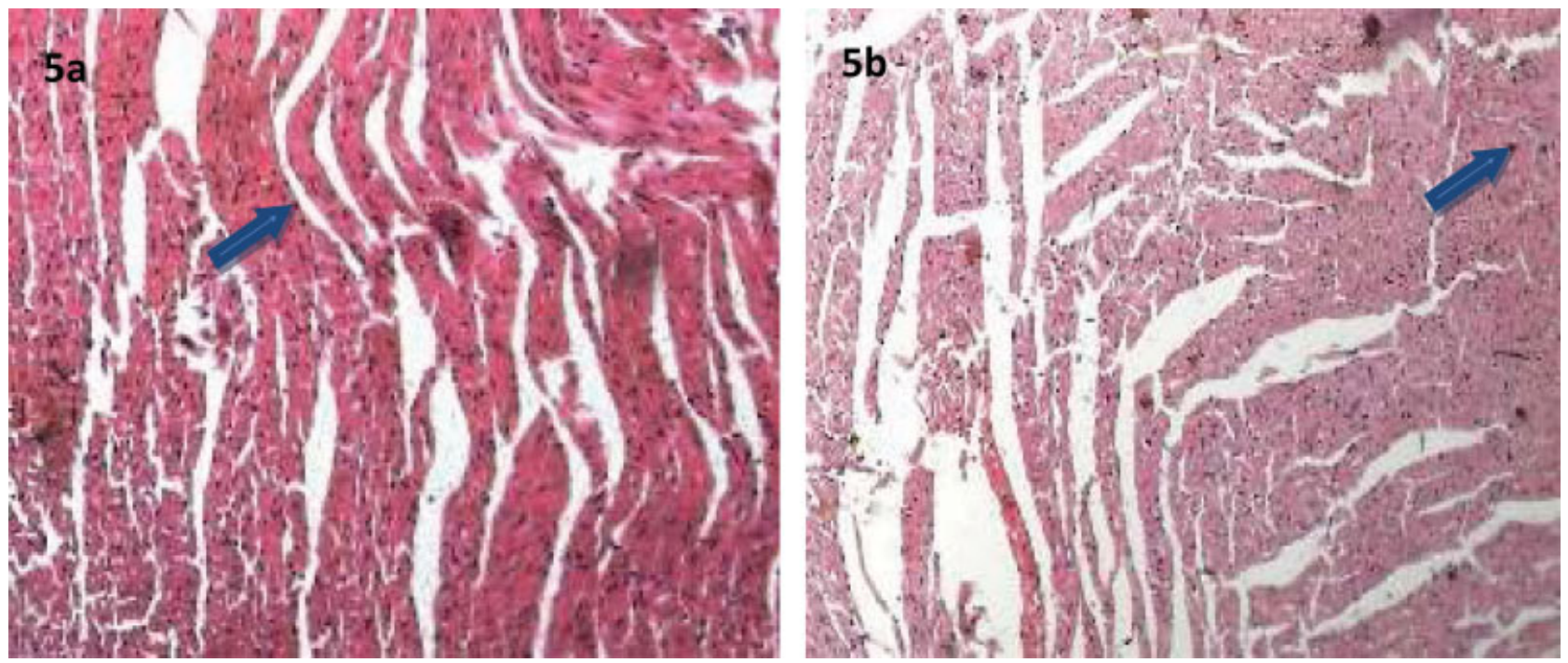

Fig. 5 (A) Photomicrograph of a cross section of normal myocardium indicating myocytes (arrowed) separated by interstitium. Hematoxylin and eosin stained. Mag. X100. (B) Photomicrograph of a cross section of cardiac tissue treated with $200 \mathrm{mg} / \mathrm{kg}^{-1}$ of the extract showed normal myocytes (arrowed) and normal interstitium. Hematoxylin and eosin stained. Mag. X100.

animal models to predict toxicity and to provide guidelines for selecting a safe dose in humans.

The acute toxicity study showed that S. afzelii extract may be generally regarded to be safe with remote risk of acute intoxication since the animals tolerated up to $9 \mathrm{~g} / \mathrm{kg}^{-1}$ bwt by gavages. More so, it showed much higher value than the World Health Organization's (WHO) toxicity index of $2 \mathrm{~g} / \mathrm{kg}^{-1} \mathrm{bwt}^{7}$ The high degree of safety could be considered consistent with its popular use locally. Concerning the effect of the extract on the body weight of the animal, the result showed initial decrease in the treated group, which later exhibited gradual recovery after 7 days. Body weight loss is known to be caused by loss of appetite, malabsorption or the presence of antinutritional elements. ${ }^{26}$ The improvement in weight, which was observed after 7 days, could therefore be due to adaptability. The gross anatomy of the organs revealed no detectable color changes, but organ weight increase was observed particularly in the testis. Increase in organ weight (organomegaly) has been noted as a sensitive indicator of adverse effect on organs, caused by standard toxicants. ${ }^{27}$ The effect of the toxicant may have been responsible for the enlargement of the testis in this regard; more so, there was no correlation to the body size of the animal.

The liver is an important organ of the body because of its crucial role in various metabolic processes, and it is, therefore, particularly exposed to the toxic effects of exogenous compounds. ${ }^{28}$ Alanine aminotransferase and AST are common liver enzymes because of their higher concentrations in hepatocytes, but only ALT is remarkably specific for liver function. ${ }^{29}$ Aspartate aminotransferase, besides being found in the liver, is also found in equal amounts in heart, muscles, kidney, etc. ${ }^{30} \mathrm{Hepa}-$ tocellular injury leads to these enzymes release into the blood 
Table 3 Blood chemistry values of rats in subchronic treatment with S. Afzelii

\begin{tabular}{|l|l|l|l|l|}
\hline Parameter & Control & 50 & 100 & 200 \\
\hline Total plasma protein $\left(\mathrm{mg} / \mathrm{dl}^{-1}\right)$ & $65.9 \pm 1.9$ & $70.4 \pm 2.7$ & $70.8 \pm 2.0$ & $68.3 \pm 3.2$ \\
\hline Albumin $\left(\mathrm{mg} / \mathrm{dl}^{-1}\right)$ & $36.6 \pm 2.2$ & $57.3 \pm 1.5^{*}$ & $39.9 \pm 3.0$ & $39.1 \pm 3.2$ \\
\hline Total bilirubin $\left(\mathrm{mg} / \mathrm{dl}^{-1}\right)$ & $1.4 \pm 0.1$ & $0.6 \pm 0.0$ & $0.6 \pm 0.1$ & $0.6 \pm 0.0$ \\
\hline AST $\left(\mathrm{i} \mu / \mathrm{L}^{-1}\right)$ & $112.1 \pm 4.4$ & $123.2 \pm 2.6^{* *}$ & $124.5 \pm 2.2^{* *}$ & $127.9 \pm 1.4^{*}$ \\
\hline ALT $\left(\mathrm{i} \mu / \mathrm{L}^{-1}\right)$ & $59.5 \pm 3.1$ & $77.2 \pm 1.4$ & $60.7 \pm 2.2$ & $47.6 \pm 2.4$ \\
\hline Alkaline phosphatase $\left(\mathrm{i \mu} / \mathrm{L}^{-1}\right)$ & $160.5 \pm 2.4$ & $170.2 \pm 3.3$ & $169.2 \pm 3.0$ & $141.3 \pm 8.5^{*}$ \\
\hline Urea $\left(\mathrm{mg} / \mathrm{dl}^{-1}\right)$ & $8.9 \pm 1.6$ & $7.9 \pm 0.3$ & $9.8 \pm 0.6$ & $9.4 \pm 0.7$ \\
\hline Creatinine $\left(\mathrm{mg} / \mathrm{dl}^{-1}\right)$ & $39.5 \pm 1.1$ & $48.8 \pm 0.1$ & $46.7 \pm 1.5$ & $35.8 \pm 3.7$ \\
\hline Total cholesterol $\left(\mathrm{mg} / \mathrm{dl}^{-1}\right)$ & $90.0 \pm 0.2$ & $87.4 \pm 0.5$ & $99.4 \pm 0.4$ & $95.3 \pm 0.2$ \\
\hline Triglycerides $\left(\mathrm{mg} / \mathrm{dl}^{-1}\right)$ & $56.2 \pm 0.4$ & $77.5 \pm 0.1^{*}$ & $58.6 \pm 0.1$ & $67.12 \pm 0.4^{*}$ \\
\hline HDL-cholesterol $\left(\mathrm{mg} / \mathrm{dl}^{-1}\right)$ & $41.1 \pm 0.1$ & $38.3 \pm 0.1$ & $38.2 \pm 0.1$ & $44.0 \pm 0.1$ \\
\hline
\end{tabular}

Abbreviations: Alt, alanine aminotransferase; AST, aspartate aminotransferase; HDL, high-density lipoprotein.

Mean \pm SEM, $(n=5){ }^{*} p<0.05 ;{ }^{* *} p<0.01$ versus control group.

Table 4 Hematological values of rats in subchronic treatment with S. Afzelii extract

\begin{tabular}{|l|l|l|l|l|l|l|l|}
\hline Treatment & $\underline{\text { RBC }\left(\times 10^{6}\right)}$ & $\underline{\mathrm{Hb}(\mathrm{g} / \mathrm{dl})}$ & $\underline{\text { PCV (\%) }}$ & $\underline{\text { WBC }\left(\mathbf{x 1 0 ^ { 3 } )}\right.}$ & $\underline{\text { MCV (fl) }}$ & $\underline{\text { MCH (\%) }}$ & $\underline{\text { MCHC (\%) }}$ \\
\hline Control & $7.0 \pm 0.1$ & $10.5 \pm 1.0$ & $39.9 \pm 0.9$ & $4.6 \pm 0.2$ & $56.2 \pm 1.2$ & $16.1 \pm 1.1$ & $28.3 \pm 01.1$ \\
\hline $50 \mathrm{mg} / \mathrm{kg}^{-1}$ & $5.7 \pm 0.5$ & $10.3 \pm 0.5$ & $33.9 \pm 2.0$ & $9.2 \pm 1.5$ & $57.8 \pm 1.1$ & $17.6 \pm 0.7$ & $30.5 \pm 1.6$ \\
\hline $100 \mathrm{mg} / \mathrm{kg}^{-1}$ & $5.7 \pm 0.2$ & $10.1 \pm 1.3$ & $34.5 \pm 0.2$ & $7.6 \pm 1.1$ & $58.5 \pm 4.11$ & $18.0 \pm 0.8$ & $30.7 \pm 1.1$ \\
\hline $200 \mathrm{mg} / \mathrm{kg}^{-1}$ & $5.7 \pm 0.8$ & $10.4 \pm 2.5$ & $44.5 \pm 2.5$ & $5.2 \pm 0.5$ & $59.0 \pm 7.3$ & $18.4 \pm 2.1$ & $29.9 \pm 0.9$ \\
\hline
\end{tabular}

Abbreviations: $\mathrm{Hb}$, hemoglobin; $\mathrm{MCH}$, mean corpuscular hemoglobin; $\mathrm{MCHC}$, mean corpuscular hemoglobin concentration; MCV, mean corpuscular volume; PCV, packed cell volume; RBC, red blood cell; WBC, white blood cell.

Mean \pm SEM, $(n=5){ }^{*} \mathrm{p}<0.05 ;{ }^{* *} p<0.01$ versus control group.

Table 5 Quantitative data on white blood cell differentials in rats after sub-chronic treatment with S. Afzelii extract

\begin{tabular}{|l|l|l|l|l|l|}
\hline Treatment & Neutrophil \% & Lymphocyte \% & Lymphocyte ABS & MXD \% & Platelet \% \\
\hline Control & $0.3 \pm 0.1$ & $62.6 \pm 2.5$ & $6.3 \pm 1.2$ & $23.3 \pm 2.3$ & $70.0 \pm 1.6$ \\
\hline $50 \mathrm{mg} / \mathrm{kg}^{-1}$ & $2.4 \pm 0.8{ }^{* *}$ & $73.9 \pm 4.04^{*}$ & $6.8 \pm 1.0$ & $26.0 \pm 4.0$ & $84.4 \pm 2.8^{*}$ \\
\hline $100 \mathrm{mg} / \mathrm{kg}^{-1}$ & $1.2 \pm 0.2$ & $82.5 \pm 1.1^{*}$ & $6.3 \pm 1.3$ & $13.2 \pm 1.2$ & $62.2 \pm 1.6^{*}$ \\
\hline$\underline{200 \mathrm{mg} / \mathrm{kg}^{-1}}$ & $\underline{1.4} \pm \underline{0.3}$ & $\underline{71.9} \pm \underline{4.2^{*}}$ & $\underline{4.0 \pm \underline{0.4}}$ & $\underline{25.4} \pm \underline{0.4}$ & $\underline{76.7} \pm \underline{4.2^{* *}}$ \\
\hline
\end{tabular}

Abbreviations: Lymphocyte ABS, lymphocyte absolute count; MXD, mixed differential.

Mean \pm standard error of the mean (SEM), $(n=5){ }^{*} \mathrm{p}<0.05 ;{ }^{* *} p<0.01$ versus control group.

stream and their quantification in blood plasma is a useful biomarker to determine the extent and type of hepatocellular damage. ${ }^{31}$ Hepatic tissue morphology of the treated groups showed normal cellular appearance with no hepatocellular damage. This finding also corroborated with the biochemical result in which the ALT plasma level was within the normal range. The appreciable increase observed in AST blood plasma could be attributable to the cytotoxic effect of the extract on other organs, since this enzyme is not liver-specific. In this case, the extract may have been implicated in testicular inflammatory changes. There was quantitative decrease in spermatogenic cells due to extensive cellular necrosis, leaving only the basement layer of the seminiferous tubules. Total plasma protein and ALB showed an increase in plasma levels, which was indicative that the extract helped to prevent oxidative damage to the liver. Increase in plasma level of these proteins is reported to have hepato-protective effect. ${ }^{32}$ There was, however, a decrease in the plasma T. BIL level. Plasma bilirubin could be expressed as T.BIL, comprising of conjugated and nonconjugated, or as direct bilirubin, comprising only of the conjugated form. An increase in the plasma bilirubin level could be attributed to three major causes, such as hemolysis, biliary obstruction and liver cell necrosis. ${ }^{33,34}$ The decrease observed in this study further confirmed that the extract had no deleterious effect on the liver. Alkaline phosphate showed insignificant increase at low and medium doses but decreased at the highest treatment dose. Alkaline phosphate is a marker enzyme present in high concentrations in the liver, and when hepatocytes are inflamed or damaged, these enzymes leak into the blood stream, leading to a rise in the plasma level of these enzymes. ${ }^{35}$ 
The kidney, much like the liver, plays a vital role in metabolizing toxic substances. Creatinine and urea, the two byproducts of protein breakdown in the urinary system, are used as quantitative measure for kidney damage. An increase in the plasma creatinine level suggests kidney damage, more specifically damage to the renal filtration mechanism. ${ }^{18,36}$ These end-products of protein metabolism, however, showed insignificant variation from the control group in this study, indicating that the risk of potential inflammatory challenge was minimal. Similarly, the tissue histology of the kidney of the extract-treated animals showed normal appearance, further confirming that the extract had no nephrotoxic effect. The extract also did not exhibit cardio-toxic effect, based on cardiac tissue morphology that showed normal appearance.

Hematological analysis of the plant extract is considered an important mode of assessing the toxicity of plants, having been noted as a major indicator of toxicity in phytomedicine. ${ }^{8,37}$ There was a decrease in RBC, hemoglobin $(\mathrm{Hb})$ and PCV values, except for the $200 \mathrm{~g} / \mathrm{kg}^{-1}$ dose of the latter, suggesting decrease in erythropoiesis and the oxygen-caring capacity of blood and the amount of the oxygen delivered to the tissues. ${ }^{38}$ The decrease in $\mathrm{Hb}$ level also suggested the likelihood of decrease in iron absorption. The RBC indices, $\mathrm{MCHC}, \mathrm{MCH}$ and $\mathrm{MCV}$ exhibited insignificant increase, respectively. Increase in these parameters suggested that macrocytic anemia occurred, which is believed to be linked to iron deficiency. ${ }^{39}$ The WBC count also showed increase, which might be due to challenge in body defense system. The WBC differentials, lymphocytes and neutrophils showed increase with more marked increase observed in lymphocyte which is the main effectors cell of the immune system. ${ }^{40}$ Likewise, there was a stimulatory increase in lymphocyte that may have been triggered by the extract toxic challenge on the testis, which, in this case, appeared most vulnerable with extensive sperm cells damage. The increased neutrophil was indicative that the WBC differential was active as a phagocytic agent against foreign compounds. Neutrophil level is known to rise when there is an increased need for phagocytosis of damaged tissues. ${ }^{7}$ The increase in the platelet count may have resulted from the stimulatory effect on thrombopoietin production. ${ }^{41}$

\section{Conclusion}

S. afzelii exhibited high safety margin, an indication that is safe for consumption. The prolonged administration of the extract did not provoke hepatotoxic, nephrotoxic and cardiotoxic effects. However, the quantitative decrease in spermatogenic cells in the extract treated group suggests that in chronic administration it might pose a threat to male fertility.

\section{References}

1 WHO. Screening for Type 2 Diabetes: Report of WHO and International Diabetes Federation Meeting. WHO, Geneva, 2003

2 Ogbonnia SO, Odimegwu JI, Enwuru VN. Evaluation of hypoglycaemic and hypolipidaemic effects of aqueous ethanolic extracts of Treculia africana Decne and Bryophyllum pinnatum Lam. And their mixture on streptozotocin (STZ)-induced diabetic rats. Afr J Biotechnol 2008;7(15):2535-2539
3 Fauci AS, Braunwald E, Kasper DL, et al. Harrison's Principles of Internal Medicine. 17th ed. United States: McGraw-Hill Professional, 2008

4 Ahsan MR, Islam KM, Haque ME, Mossaddik MA. In vitro antibacterial screening and toxicity study of some different medicinal plants. World J Agric Sci 2009;5(05):617-621

5 Elvin-Lewis M. Should we be concerned about herbal remedies. J Ethnopharmacol 2001;75(2-3):141-164Doi: 10.1016/S03788741(00)00394-9

6 Chan K. Some aspects of toxic contaminants in herbal medicines. Chemosphere 2003;52(09):1361-1371

7 Mbaka GO, Ogbonnia SO, Awoyemi FO. Acute and sub-acute toxicity studies of ethanol seed extract of raphia hookeri on Swiss albino rats. Br J Pharm Res 2014a4(10):1196-1208Doi: 10.9734/ BJPR/2014/9330

8 Tanayen JK, Ezeonwumelu JOC, Ajayi AM, et al. Evaluation of the acute and sub chronic toxicities of the methanolic stem bark extract of Spathodea campanulata (P. Beauv.) Bignoniaceae. $\mathrm{Br} J$ Pharmacol Toxicol 2016;7(01):9-19Doi: 10.19026/bjpt.7.2804

9 Goyder DJ. Secamone afzelii (Asclepiadaceaesubfam. Secamonoideae) in Africa. Kew Bull 1992;47:437-474

10 Odugbemi T. Outlines and pictures of medicinal plants in Nigeria. 6th ed. University of Lagos Press; 2006:43-4

11 Kayode J. Ethnomedicinal survey of botanicals used in treating sexually transmitted diseases in Ekiti State, Nigeria. Ethnobotany Leaflets 2008;12:44-55

12 Mbaka G, Anunobi C, Ogunsina S, Osiagwu D. Histomorphological changes in induced benign prostatic hyperplasia with exogenous testosterone and estradiol in adult male rats treated with aqueous ethanol extract of Secamone afzelii.. Egyptian Journal of Basic and Applied Sciences 2017;4:15-21Doi: 10.1016/j.ejbas.2016.11.003

13 Mensah AY, Houghton PJ, Akyirem GN, et al. Evaluation of the antioxidant and free radical scavenging properties of Secamone afzelii Rhoem. Phytother Res 2004;18(12):1031-1032Doi: 10.1002/ ptr.1614

14 Institute of Laboratory Animal Research (ILAR). Commission on life science. Washington: National Academy Press; 1996. Available from: http:// www.nap.edu/ catalog/5140.html.

15 Mbaka GO, Ogbonnia SO, Olubamido TO, Awopetu PI, Ota DA. Evaluation of Acute and Sub-chronic Toxicities of Aqueous Ethanol Root Extract of Raphia hookeri (Palmaceae) on Swiss Albino Rats. Br J Pharmacol Toxicol 2014b5(04):129-135

16 Pieme CA, Penlap VN, Nkegoum B, Taziebou CL, Tekwe EM, Etoa FX. Evaluation of acute and subacute toxicities of aqueous ethanol extract of leaves of Senna alata (L.) Roxb (Ceasal piniaceae). Afr J Biotechnol 2006;5(03):283-289

17 Joshi CS, Priya ES, Venkataraman S. Acute and sub acute studies on the poly herbal anti diabetic formulation Diakyur in experimental animal model. J Health Sci 2007;53(02):245-249 URL http:// scialert.net/abstract/?doi=ijp.2008.388.392

18 Wasan KM, Najafi S, Wong J, Kwong M, Pritchard PH. Assessing plasma lipid levels, body weight, and hepatic and renal toxicity following chronic oral administration of a water soluble phytostanol compound, FM-VP4, to gerbils. J Pharm Pharm Sci 2001;4 (03):228-234www.ualberta.ca/ csps

19 Sushruta K, Satyanarayana S, Srinivas N, Sekhar RJ. Evaluation of the blood-glucose reducing effects of aqueous extracts of the selected umbellifereous fruits used in culinary practice. Trop J Pharm Res 2006;5(02):613-617

20 Weatherburn MW. Phenol-hypochlorite reaction for determination of ammonia. Anal Chem 1967;39:971-974

21 Ali Hussain HE, Eshrat HM. Hypoglycemic, hypolipidemic and antioxidant properties of combination ofCurcumin fromCurcuma longa, Linn, and partially purified product fromAbroma augusta, Linn. in streptozotocin induced diabetes. Indian J Clin Biochem 2002;17(02):33-43Doi: 10.1007/BF02867969 
22 Koch TR, Doumas BT. Bilirubin, total and conjugated, modified Jendrassik Grot method. In selected methods of clinical chemistry vol. 9, edited by W Faulkner and S Meites. Washington DC: American Association of Clinical Chemistry; 1982:113

23 Spencer K, Price CP. Determination of serum albumin using Bromoscresol techniques. Ann Clin Biochem 1971;14:105-115

24 Ekaidem IS, Akpanabiatu MI, Uboh FE, Eka OU. Vitamin B12 supplementation: Effects on some biochemical and haematological indices of rats on phenytoin administration. Biokemistri 2006;18(01):31-37

25 DACIE, JC. and LEWIS, SMPractical haematology 5th Edn. Churchill LivingstoneLondon 1984

26 Ilodigwe E, Akah P, Nworu C. Evaluation of the acute and subchronic toxicities of the ethanol leaf extract of Spathodea campanulata P. Beauv. Int J Appl Res Nat Prod 2010;3(02):17-21

27 Dioka C, Orisakwe OE, Afonne OJ, Agbasi PU, Akumka DD, Okonkwo DJ. Investigation into the haematologic and hepatotoxic effects of rinbacin in rats. J Health Sci 2002;48(05):393-398

28 Bihde RM, Ghosh S. Acute and subchronic (28-day) oral toxicity study in rats fed with novel surfactants. AAPS Pharmaceutical Scientists 2004;6(02):1-10

29 Crook MA. Clinical Chemistry and Metabolic Medicine. 7th edn. Hodder ArnoldLondon2006:426

30 Mohammed AM, Wudil AJ, Alhassan IU, Muhammad A, Abdulmumin Y. Acute and Subchronic Toxicity Studies of Aqueous, Methanolic and n-Hexane Root Extracts of Curcuma longa L. on Albino Rats. Br J Pharm Res 2016;14(02):1-8Doi: 10.9734/BJPR/2016/27237

31 Rexlin Sujila SM, Rajadurai M, Rexlin Shairibha SM. Hepatoprotective effect of $\beta$-sitosterol on lipid peroxidation and antioxidant status in ethanol-induced hepatotoxic rats. Int J Integr Sci Innov Technol 2014;3(04):1-11
32 Oyagbemi AA, Saba AB, Arowolo ROA. Safety evaluation of prolonged administration of stresroak in grower cockerels. Int J Poult Sci 2008;7(06):1-5

33 Tilkian M, Sarko CBM, Tilkian GA. Clinical Implication of Laboratory Tests. 2nd ed. MissouriUnited States: The C. V Mosby Co.1979

34 Farrugia A. Albumin usage in clinical medicine: tradition or therapeutic? Transfus Med Rev 2010;24(01):53-63Doi: 10.1016/j. tmrv.2009.09.005

35 Nkosi CZ, Opoku AR, Terblanche SE. Effect of pumpkin seed (Cucurbita pepo) protein isolate on the activity levels of certain plasma enzymes in CCl4-induced liver injury in low-protein fed rats. Phytother Res 2005;19(04):341-345Doi: 10.1002/ptr.1685

36 Ajayi OB, Akomolafe SF, Malachi OI, Oyerinde AS. Effect of Sesamum indicum $L$. Seed oil supplementation on the kidney function parameters of hypercholesterolemic rats. J Nutr Food Sci 2014;4:155-306Doi: 10.4172/2155-9600.1000306

37 Ashafa AOT, Yakubu MT, Grierson DS, Afolayan AJ. Toxicological evaluation of the aqueous extract of Felicia muricata leaves in wistar rats. Afr J Biotechnol 2009;6:949-954https://www.ajol. info/index.php/ajb/article/view/59991

38 De Gruchy GC. Clinical Haematology in Medical Practice. Blackwell Scientific PublicationOxford, London1976:33-57

39 Agbor GA, Oben M, Knight DC, Mills RG, Bry JJ, Crag PA. Human physiology. 4th Ed. Churchill Livingstone; 2005:290-294

40 Teguia A, Telefo PB, Fotso RG. Growth performances, organ development and blood parameters of rats fed graded levels of steeped and cooked taro tuber (Esculenta) meal. Livest Res Rural Dev 2007;19(06):1-8

$41 \mathrm{Li} \mathrm{J}$, Xia Y, Kuter DJ. Interaction of thrombopoietin with the platelet c-mpl receptor in plasma: binding, internalization, stability and pharmacokinetics. Br J Haematol 1999;106(02):345-356 